\title{
Organic Salts as p-Type Dopants for Efficient LiTFSI-free Perovskite Solar Cells
}

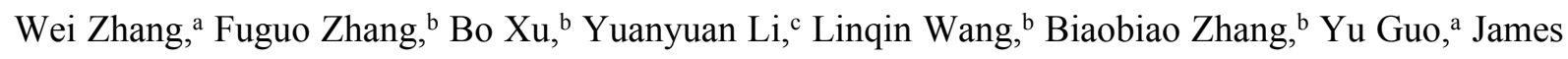
M. Gardner, ${ }^{a}$ Licheng Sun, ${ }^{\text {b, d }}$ and Lars Kloo ${ }^{\mathrm{a}^{*}}$

a) Department of Chemistry, Applied Physical Chemistry, KTH Royal Institute of Technology, SE10044 Stockholm, Sweden

b) Department of Chemistry, Organic Chemistry, KTH Royal Institute of Technology, SE-10044 Stockholm, Sweden

c) Wallenberg Wood Science Center, Department of Fiber and Polymer Technology, KTH Royal Institute of Technology, SE-10044 Stockholm, Sweden

d) State Key Laboratory of Fine Chemicals, DUT-KTH Joint Research Center on Molecular Devices, Dalian University of Technology (DUT), 116024 Dalian, China 


\section{Materials}

Chemicals and solvents were purchased from Sigma Aldrich and were used without further purification, except when explicitly mentioned below. 2,2',7,7'-Tetrakis[N,N-di(4-methoxyphenyl)amino]-9,9'spirobifluorene (Spiro-OMeTAD 99.8\%) was purchased from Borun New Material. Lead iodide $\left(\mathrm{PbI}_{2}\right.$ 99.99\%) and lead bromide $\left(\mathrm{PbBr}_{2}\right.$ 99.99\%) were purchased from TCI and Alfa Aesar, respectively. Formamidinium iodide $\left(\mathrm{CH}\left(\mathrm{NH}_{2}\right)_{2} \mathrm{I} ; \mathrm{FAI}\right)(>98 \%)$ and methylammonium bromide $\left(\mathrm{CH}_{3} \mathrm{NH}_{3} \mathrm{Br} ; \mathrm{MABr}\right)$ $(>98 \%)$ were obtained from Dyenamo and were recrystallized from absolute ethanol before use. Tris(2(1H-pyrazol-1-yl)-4-tert-butylpyridine)cobalt(III) tri[bis(trifluoromethane)sulfonimide] (FK 209) (98\%) was also obtained from Dyenamo.

\section{Synthetic Route}

Synthetic route of (MeO-TPD)TFSI and (TBD)TFSI is shown in Figure S1, details are shown as below.

\section{MeO-TPD(TFSI)}

$N, N, N^{\prime}, N^{\prime}$-Tetrakis(4-methoxyphenyl)benzidine (MeO-TPD) (304 mg, 98\%) was dissolved in $30 \mathrm{~mL}$ degassed DCM. AgTFSI (213 mg, 97\%) was then added in one portion. The solution changes color immediately from pare yellow to dark red. The solution was further stirred under $\mathrm{N}_{2}$ atmosphere at room temperature for 24 hours. Filtration three times to completely get rid of Ag particles, the filtrate was then concentrated by rotary evaporator and precipitate in diethyl ether, affording a black powder (424 mg, 95.4\% yield). Elemental Analysis: Expected: C 58.87, H 4.23, F 13.30, N 4.90, S 7.48; Found: C 55.26, H 4.52, F 11.10, N 4.68, S 7.38.

\section{TBD(TFSI)}

TBD(TFSI) was synthesized by dissolving $N, N, N^{\prime}, N^{\prime}$-Tetramethylbenzidine (TBD) (120 mg, $\left.\geq 95 \%\right)$ in $30 \mathrm{~mL}$ degassed DCM. AgTFSI (213 mg, 97\%) was then added in one portion. The solution changes color immediately from grey to dark green. The solution was further stirred under $\mathrm{N}_{2}$ atmosphere at room temperature, dark green precipitate more than $\mathrm{Ag}$ powder was observed after 24 hours. Concentration to get rid of all the solvent, re-dissolve in acetone, filtration three times to remove any Ag particles. The filtrate was then concentrated by rotary evaporator and precipitate in diethyl ether, affording a dark green powder (175 mg, 67.2\% yield). Elemental Analysis: Expected: C 44.26, H 4.13, F 23.34, N 8.60, S 13.13; Found: C 41.23, H 4.39, F 19.69, N 8.16, S 12.25.

\section{Conductivity measurements}

The conductivity of the HTMs formed was investigated according to literature reports ${ }^{20-21}$. Glass substrates without conductive layer were sequentially washed with soap, acetone, and alcohol by sonication for 30 minutes. A mesoporous $\mathrm{TiO}_{2}$ layer was made by spin-coating at $3000 \mathrm{rpm}$ for $30 \mathrm{~s}$ using a solution of $30 \mathrm{~nm} \mathrm{TiO}{ }_{2}$ paste (Dyesol DSL 30NR-T) in absolute ethanol (w/w=1/3). After spincoating, the substrate was immediately placed on a hotplate at $80{ }^{\circ} \mathrm{C}$ for $15 \mathrm{~min}$, and then transferred to an oven and sintered at $500{ }^{\circ} \mathrm{C}$ for $30 \mathrm{~min} .20 \mathrm{mg} / \mathrm{mL}$ HTM in THF was subsequently spin-coated on the mesoporous $\mathrm{TiO}_{2}$ layer, followed by evaporation of $80 \mathrm{~nm}$ gold as counter electrode. $J-V$ characteristics were recorded in the dark with a Keithley 2400 Semiconductor Characterization System.

\section{Fabrication of solar cells}

FTO glass substrates with $<15(\Omega / \mathrm{sq})$ sheet resistance (Pilkington TEC 15$)$ were cut into $12.5 \mathrm{~cm} \times 3$ $\mathrm{cm}$ pieces. These pieces were etched with $\mathrm{Zn}$ powder $/ 2 \mathrm{M} \mathrm{HCl}$ solution. After etching, all the residuals on the glass substrates were removed and washed with soap, acetone and ethanol by sonication for 30 minutes. The cleaned glass substrates were stored in ambient atmosphere without further treatment. 
A compact $\mathrm{TiO}_{2}$ layer was deposited by using a spray-pyrolysis technique with a $0.2 \mathrm{M}$ solution of titanium(IV) tetraisopropoxide and $2 \mathrm{M}$ acetylacetone in isopropanol at $450{ }^{\circ} \mathrm{C}$. After cooling to room temperature, the $12.5 \mathrm{~cm} \times 3 \mathrm{~cm}$ glass substrates were further cut into $2.5 \mathrm{~cm} \times 1.5 \mathrm{~cm}$ pieces.

A mesoporous $\mathrm{TiO}_{2}$ layer was positioned by spin-coating at $4500 \mathrm{rpm}$ for $30 \mathrm{~s}$ using a solution of $30 \mathrm{~nm}$ $\mathrm{TiO}_{2}$ paste (Greatcell Solar 30 NR-D) in absolute ethanol $(\mathrm{w} / \mathrm{w}=1 / 5.5)$. After spin-coating, the substrates were immediately placed on a hotplate at $80{ }^{\circ} \mathrm{C}$ for $15 \mathrm{~min}$, and then transferred to an oven and sintered at $500{ }^{\circ} \mathrm{C}$ for $30 \mathrm{~min}$.

To prepare the mesoporous $\mathrm{SnO}_{2}$ layer, $15 \%$ tin oxide colloid precursor was diluted to $2.67 \%$ by deionized water. The solution was spun onto the FTO glass $/$ compact $\mathrm{TiO}_{2}$ substrate surface at $3000 \mathrm{rpm}$ for $30 \mathrm{~s}$, and then baked on a hotplate in ambient atmosphere at $120^{\circ} \mathrm{C}$ for $20 \mathrm{~min}$.

$(\mathrm{FA})_{0.85}(\mathrm{MA})_{0.15} \mathrm{~Pb}\left(\mathrm{I}_{3}\right)_{0.85}\left(\mathrm{Br}_{3}\right)_{0.15}$ perovskite films were made by spin-coating at $4500 \mathrm{rpm}$ for $30 \mathrm{~s}$ inside a glovebox under argon atmosphere with a precursor solution containing $1.1 \mathrm{M} \mathrm{PbI}_{2}, 1 \mathrm{M} \mathrm{FAI}, 0.2 \mathrm{M}$ $\mathrm{PbBr}_{2}$ and $0.2 \mathrm{M} \mathrm{MABr}$ in a mixed solvent (DMF/DMSO=4/1 volume ratio). During spin-coating, 125 $\mu \mathrm{L}$ chlorobenzene was dropped onto the spinning substrate at $4500 \mathrm{rpm}$ after $15 \mathrm{~s}$. Finally, the substrates were immediately placed on a hotplate at $100^{\circ} \mathrm{C}$ for $30 \mathrm{~min}$.

$(\mathrm{FA})_{0.91}(\mathrm{MA})_{0.09} \mathrm{~Pb}\left(\mathrm{I}_{3}\right)_{0.91}\left(\mathrm{Br}_{3}\right)_{0.09}$ perovskite films were made by spin-coating at $1000 \mathrm{rpm}$ for $10 \mathrm{~s}$ and $6000 \mathrm{rpm}$ for 30s inside a glovebox under argon atmosphere with $1 \mathrm{~mL}$ precursor solution containing $851 \mathrm{mg} \mathrm{FAPbI}$ and $59 \mathrm{mg} \mathrm{MAPbBr}$ in a mixed solvent (DMF/DMSO=4/1 volume ratio). During spincoating, $125 \mu \mathrm{L}$ chlorobenzene was dropped onto the spinning substrate after $25 \mathrm{~s}$. The substrates were immediately placed on a hotplate at $100^{\circ} \mathrm{C}$ for $30 \mathrm{~min}$ after spin-coating.

Spiro-OMeTAD for reference was spin-coated at $4000 \mathrm{rpm}$ for $30 \mathrm{~s}$ with a precursor solution containing $70 \mathrm{mM}$ Spiro-OMeTAD, $20 \mathrm{mM}$ LiTFSI, $200 \mathrm{mM}$ TBP and $2 \mathrm{mM}$ FK209 in chlorobenzene. For (MeOTPD)TFSI-doped devices, $70 \mathrm{mM}$ Spiro-OMeTAD and $200 \mathrm{mM}$ TBP were blended with different amounts of (MeO-TPD)TFSI. MeO-TPD HTL was prepared with $70 \mathrm{mM} \mathrm{MeO-TPD,} 20 \mathrm{mM}$ LiTFSI, $200 \mathrm{mM}$ TBP and $2 \mathrm{mM}$ FK209 in chlorobenzene. All solutions were prepared inside a glovebox but spin-coated in ambient atmosphere.

The counter electrodes used consisted of an $80 \mathrm{~nm} \mathrm{Au}$ (Metalor; $\geq 99.99 \%$ trace metals basis) layer sequentially deposited under high vacuum $\left(<5 \times 10^{-5} \mathrm{~Pa}\right)$ by thermal evaporation (Edwards Auto 306) through a shadow mask to form an active area of about $0.20 \mathrm{~cm}^{2}$.

\section{Characterization of materials and solar cells}

NMR spectra were recorded on a Bruker AVANCE $400 \mathrm{MHz}$ spectrometer. XRD was recorded by a PANalytical-X'Pert PRO diffractometer using $\mathrm{Cu}-\mathrm{K} \alpha$ radiation at a voltage of $45 \mathrm{kV}$ and current of 40 $\mathrm{mA}$. The elemental analysis were conducted by Analytical Laboratory in Lindlar, Germany. EPR spectra were recorded under ambient condition on a Bruker EMX-micro spectrometer equipped with an EMXPrimium bridge and an ER4119HS resonator. Organic salts in degassed acetonitrile were prepared with a concentration of $0.3 \mathrm{mM}$ and loaded to capillary sample tubes $(50 \mu 1$ with one end open). CV and DPV were performed in $\mathrm{DCM}$ with $0.1 \mathrm{M}(\mathrm{TBA}) \mathrm{PF}_{6}$ as supporting electrolyte, an $\mathrm{Ag} / \mathrm{AgNO} \mathrm{N}_{3}$ electrode as reference, a glassy carbon electrode as working electrode, a Pt rod as counter electrode and ferrocene/ferrocenium $\left(\mathrm{Fc} / \mathrm{Fc}^{+}\right)$as an internal reference using a $\mathrm{CH}$ Instruments electrochemical workstation (model $660 \mathrm{~A}$ ). The $\mathrm{CV}$ scan rate used was $0.1 \mathrm{~V} / \mathrm{s}$. The $\mathrm{UV} / \mathrm{V}$ is absorption spectra were recorded on a Lambda 750 spectrophotometer using a $1 \mathrm{~cm}$ cuvette. The scanning electron microscopy (SEM) images were recorded on a FEI-XL 30 series microscope. The film thickness was determined by profilometer, model Veeco Dektak 150. The light source for the photocurrent-voltage $(J-V)$ measurements was an AM 1.5G solar simulator (Newport 91160-1000). The incident light intensity was $100 \mathrm{~mW} \cdot \mathrm{cm}^{-2}$ calibrated using a certified Si-photodiode (Fraunhofer ISE). The solar cells investigated were masked to a working area of $0.126 \mathrm{~cm}^{2}$. The $J-V$ relationships were obtained by the linear sweep 
voltammetry (LSV) method using a Keithley 2400 source-measure unit. Incident photon-to-electron conversion efficiency (IPCE) spectra were recorded on a computer-controlled setup with an ASB-XE175 light source, monochromator (Spectral Products CM110) and a Keithley multimeter (Model 2700). The set-up was calibrated with a certificated silicon solar cell (Fraunhofer ISE).
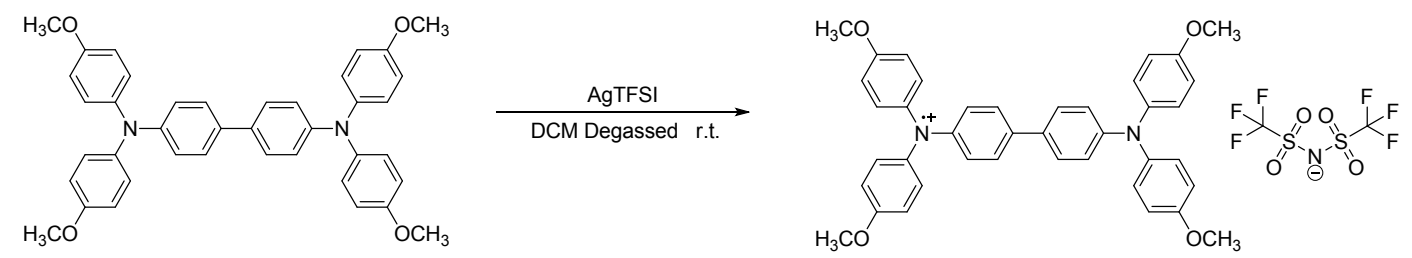

(MeO-TPD)TFSI

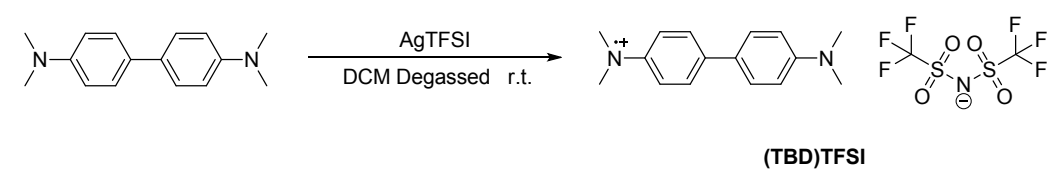

Figure S1. Synthetic route of (MeO-TPD)TFSI and (TBD)TFSI.

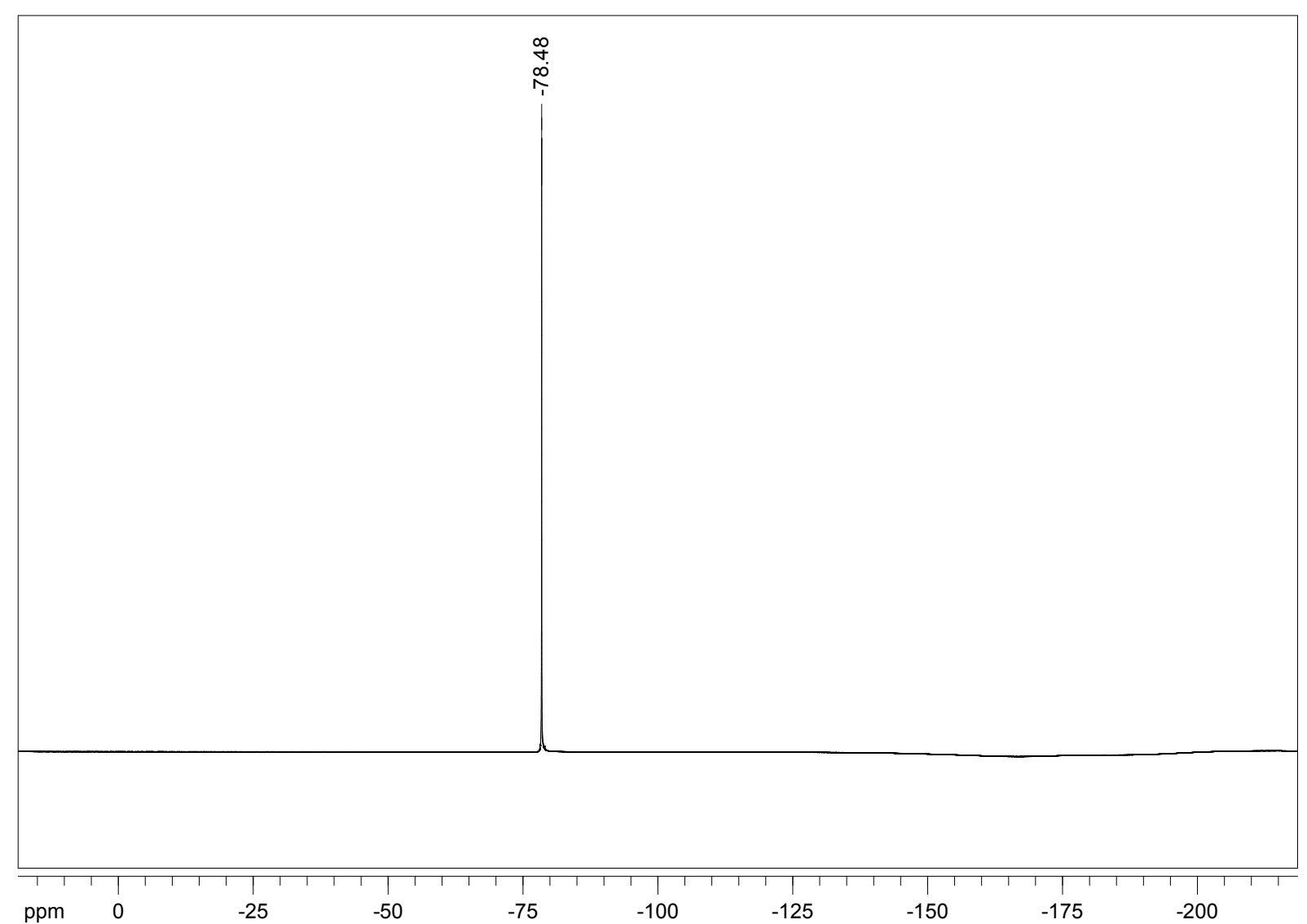

Figure S2. ${ }^{19} \mathrm{~F}$ NMR of (MeO-TPD)TFSI in $\mathrm{CDCl}_{3}$. 


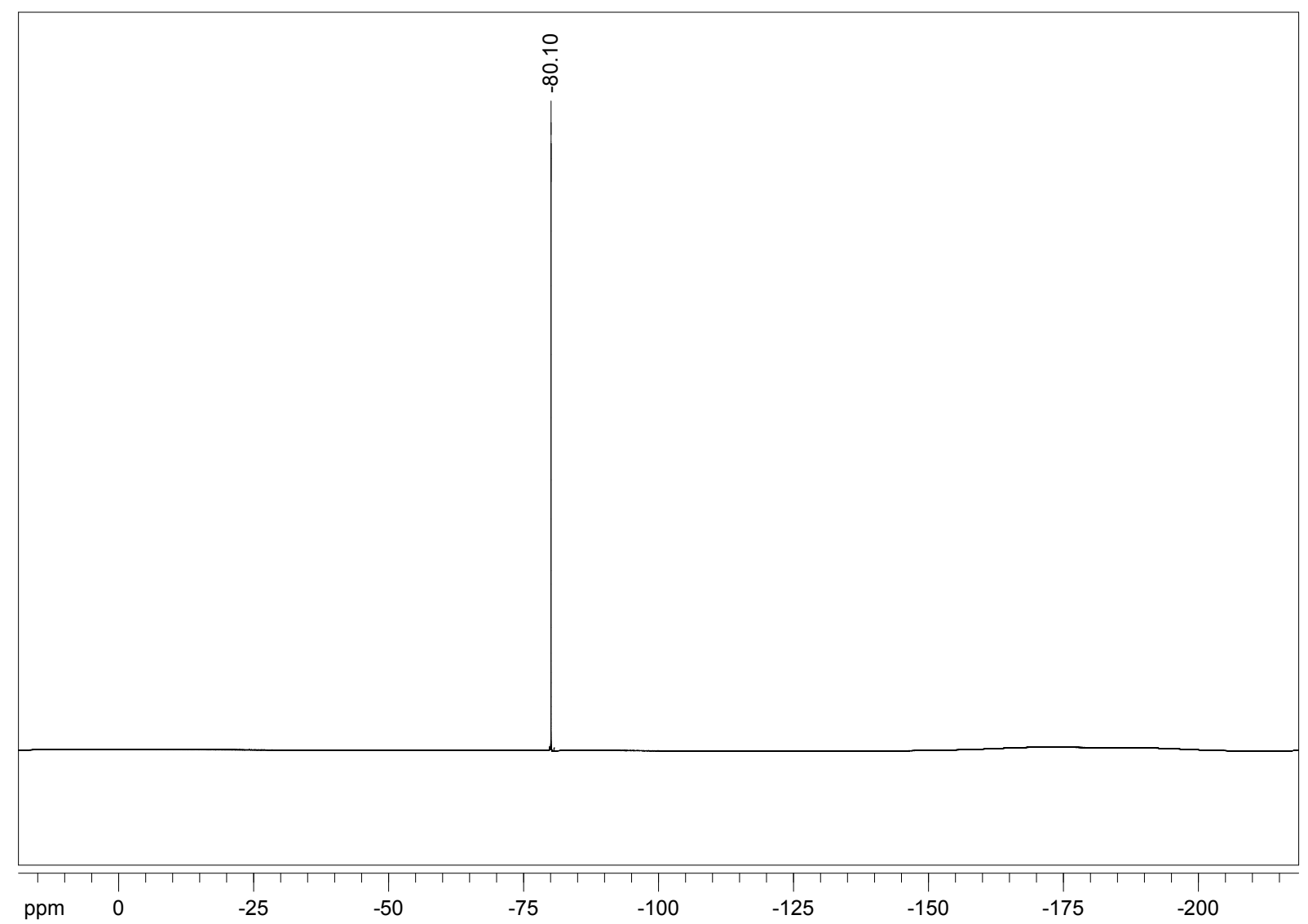

Figure S3. ${ }^{19} \mathrm{~F}$ NMR of (TBD)TFSI in MeCN-d3.
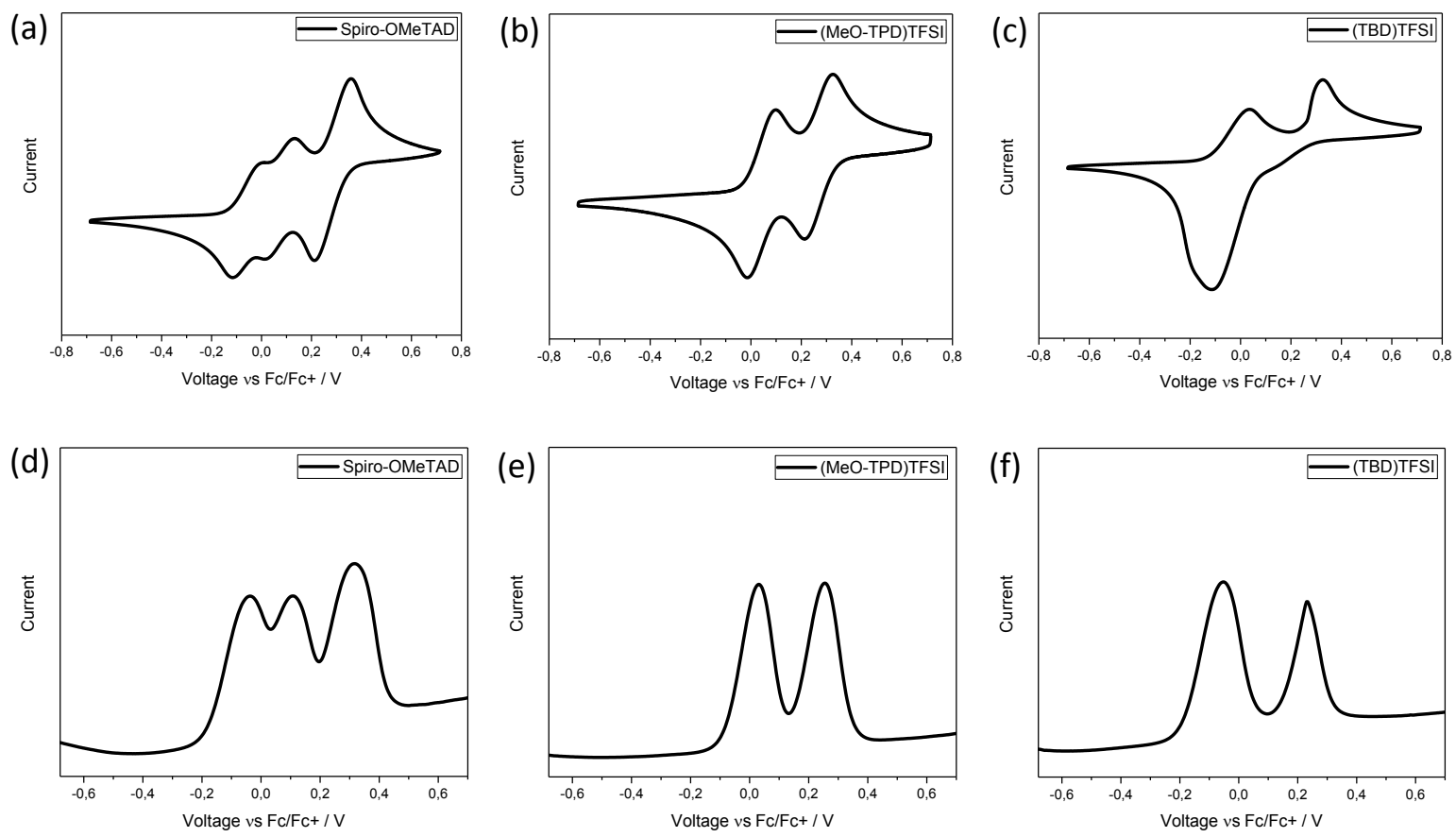

Figure S4. Cyclic voltammetry of (a) Spiro-OMeTAD, (b) (MeO-TPD)TFSI and (c) (TBD)TFSI; Differential pulse voltammetry of (d) Spiro-OMeTAD, (e) (MeO-TPD)TFSI and (f) (TBD)TFSI. 

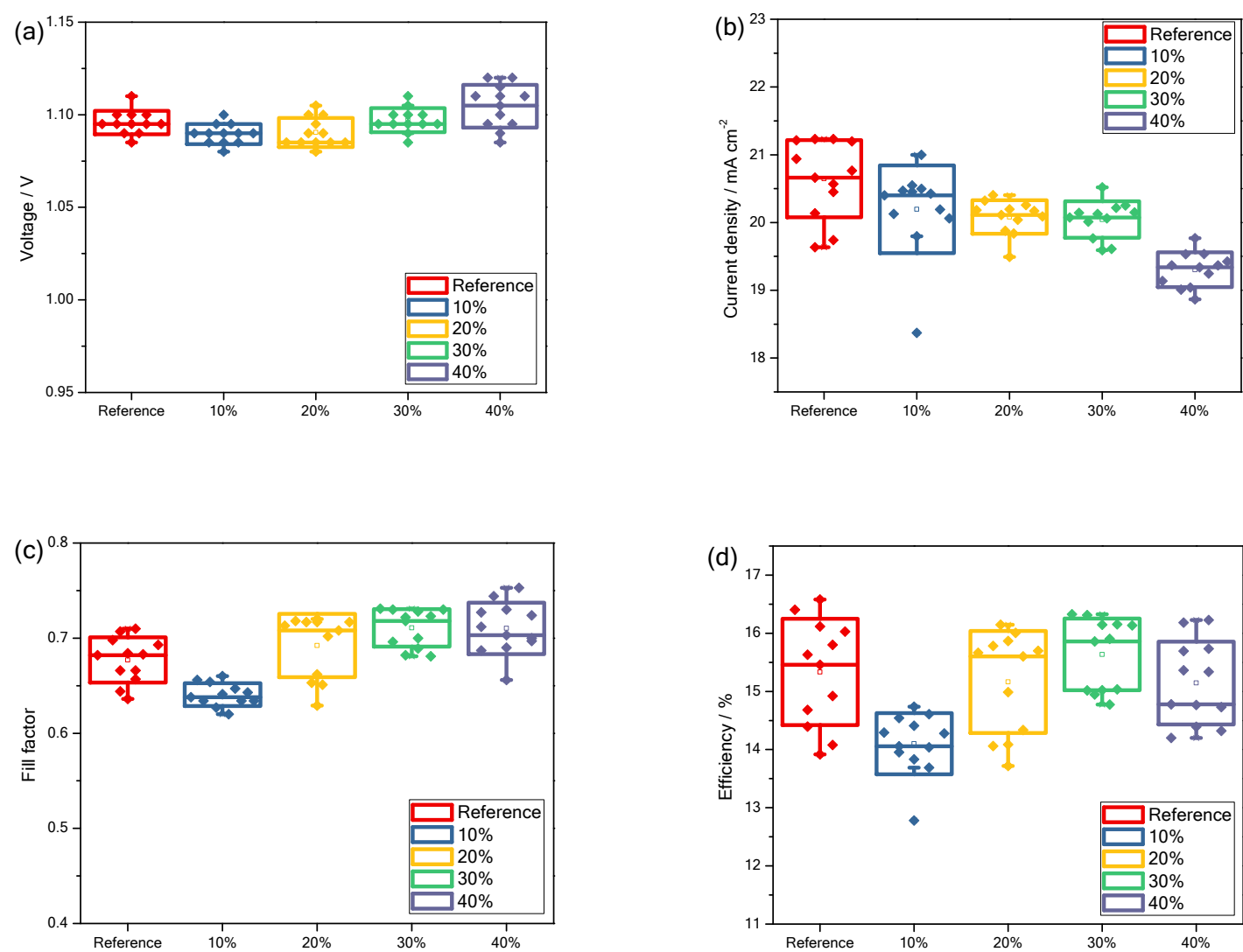

Figure S5. (a) Voltage; (b) Current density; (c) Fill factor; (d) Efficiency distribution of reference devices and those doped by MeO-TPD(TFSI) without LiTFSI. The square marker inside the box represents average values, the horizontal bar represents $50 \%$, the box is composed of $+/$ - one standard deviation, and whiskers represent $1.5 \mathrm{x}$ the interquartile range.

Table S1. Photovoltaic parameters of devices with and without LiTFSI.

\begin{tabular}{ccccc}
\hline & Voc $/ \mathbf{V}$ & Jsc $/ \mathbf{m A ~} \mathbf{~ c m}^{-2}$ & FF & $\boldsymbol{\eta} / \%$ \\
\hline $\begin{array}{c}\text { Spiro+LiTFSI+TBP+FK209 } \\
\text { (Reference) }\end{array}$ & $1.10 \pm 0.01$ & $20.7 \pm 0.6$ & $0.68 \pm 0.02$ & $15.3 \pm 0.9$ \\
\hline $\begin{array}{c}\text { Spiro+TBP+10\% (MeO- } \\
\text { TPD)TFSI }\end{array}$ & $1.09 \pm 0.01$ & $20.2 \pm 0.7$ & $0.64 \pm 0.01$ & $14.1 \pm 0.5$ \\
\hline $\begin{array}{c}\text { Spiro+TBP+20\% (MeO- } \\
\text { TPD)TFSI }\end{array}$ & $1.09 \pm 0.01$ & $20.1 \pm 0.3$ & $0.69 \pm 0.03$ & $15.2 \pm 0.9$ \\
\hline $\begin{array}{c}\text { Spiro+TBP+30\% (MeO- } \\
\text { TPD)TFSI }\end{array}$ & $1.10 \pm 0.01$ & $20.0 \pm 0.3$ & $0.71 \pm 0.02$ & $15.6 \pm 0.6$ \\
\hline $\begin{array}{c}\text { Spiro+TBP+40\% (MeO- } \\
\text { TPD)TFSI }\end{array}$ & $1.10 \pm 0.01$ & $19.3 \pm 0.3$ & $0.71 \pm 0.03$ & $15.1 \pm 0.7$ \\
\hline
\end{tabular}

Devices fabricated are based on $\mathrm{TiO} 2$ as electron transport material and $(\mathrm{FA}) 0.85(\mathrm{MA}) 0.15 \mathrm{~Pb}(\mathrm{I3}) 0.85(\mathrm{Br} 3) 0.15$ as active layer. 


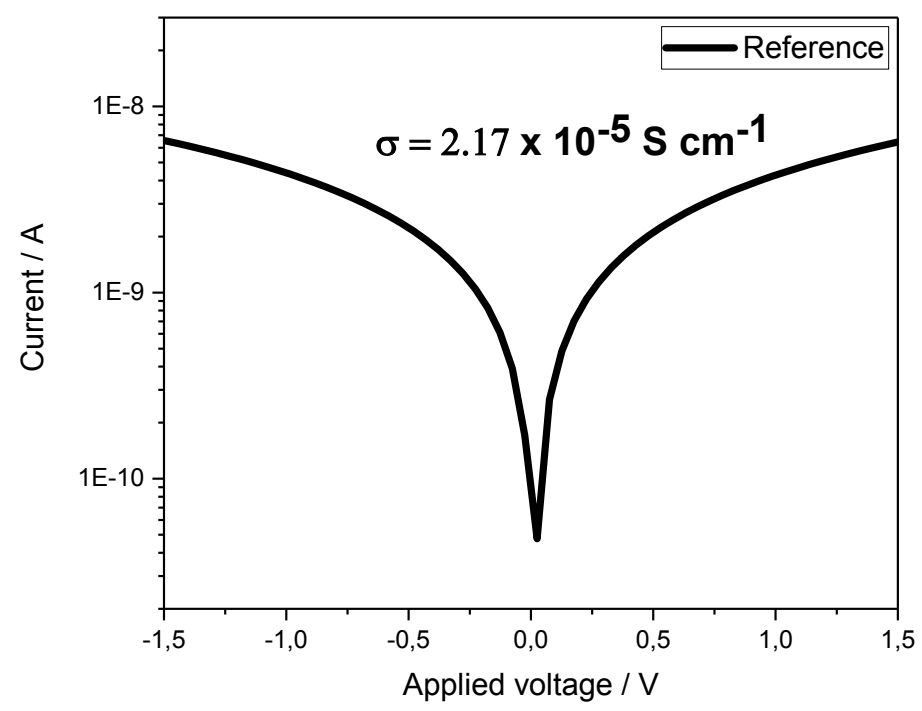

Figure S6. Current of Spiro-OMeTAD thin films (reference) under different applied voltages. Conductivity determined to be $2.17 \times 10^{-5} \mathrm{~S} \mathrm{~cm}^{-1}$.

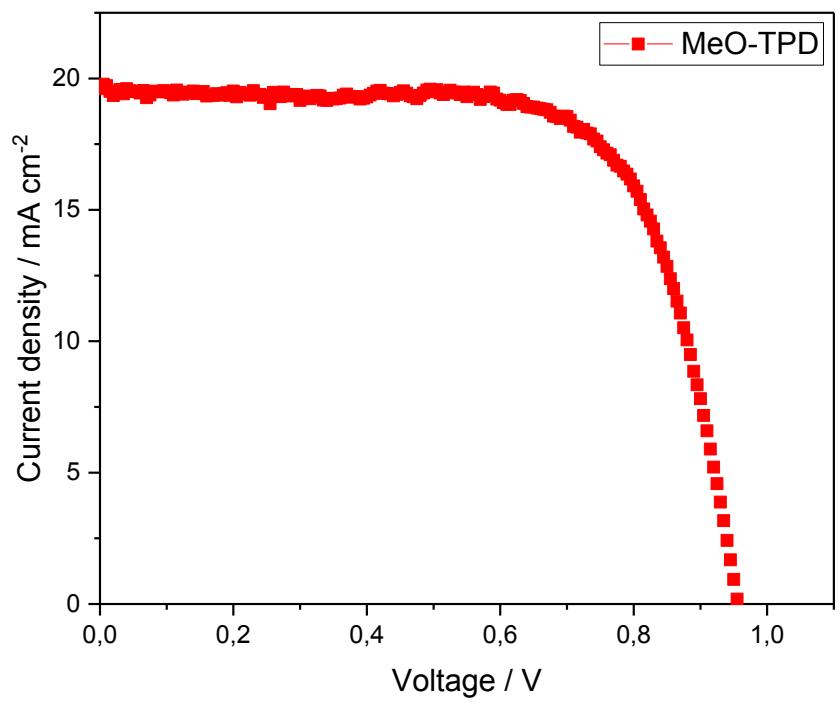

Figure S7. $J-V$ curves of MeO-TPD as HTM for perovskite solar cells.

Table S2. Photovoltaic parameters of device based on MeO-TPD as HTM.

\begin{tabular}{|c|c|c|c|c|}
\hline & $\mathrm{V}_{\text {oc }} / \mathrm{v}$ & $\mathrm{J}_{\mathrm{sc}} / \mathrm{mA} \mathrm{cm}^{-2}$ & $\mathrm{FF}$ & $\mathrm{PCE} / \%$ \\
\hline $\mathrm{MeO}-\mathrm{TPD}$ & 0.96 & 19.62 & 0.70 & 13.15 \\
\hline
\end{tabular}

Devices fabricated are based on $\mathrm{TiO} 2$ as electron transport material and (FA) $0.85(\mathrm{MA}) 0.15 \mathrm{~Pb}(\mathrm{I} 3) 0.85(\mathrm{Br} 3) 0.15$ as active layer. 


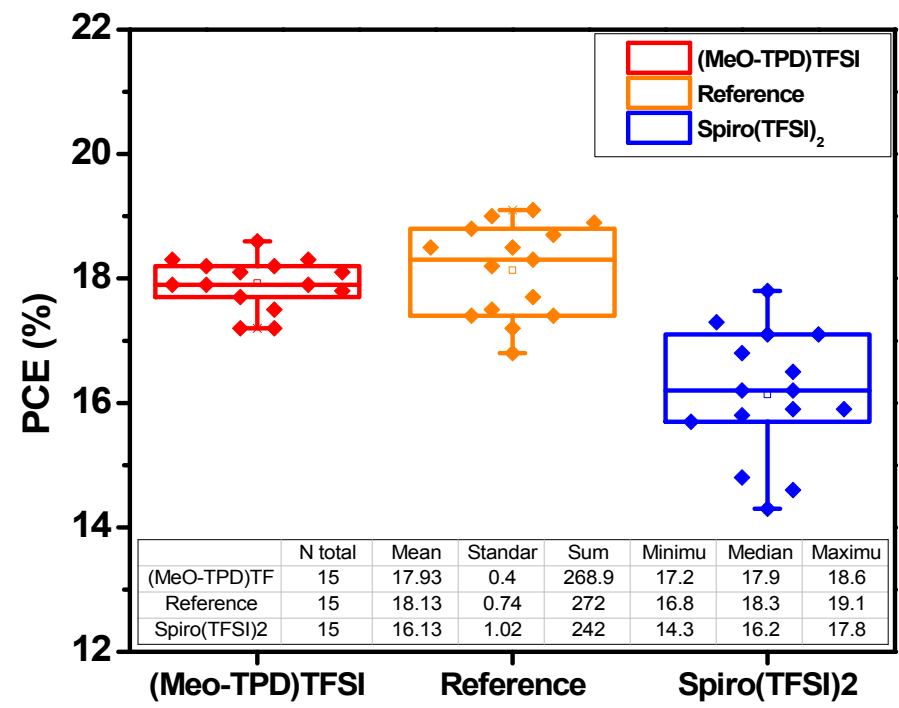

Figure S8. Distributions of device PCEs based on different dopants. The reference HTL contains LiTFSI, while the (MeO-TPD)TFSI and Spiro(TFSI $)_{2}$ doped devices do not contain LiTFSI. Devices fabricated are based on $\mathrm{SnO}_{2}$ as electron transport material and $(\mathrm{FA})_{0.91}(\mathrm{MA})_{0.09} \mathrm{~Pb}_{(}\left(\mathrm{I}_{3}\right)_{0.91}\left(\mathrm{Br}_{3}\right)_{0.09}$ as active layer. The square marker inside the box represents average values, the horizontal bar represents $50 \%$, the box is composed of $25 \mathrm{th} / 75$ th percentiles, and whiskers represent $1.5 \mathrm{x}$ the interquartile range.

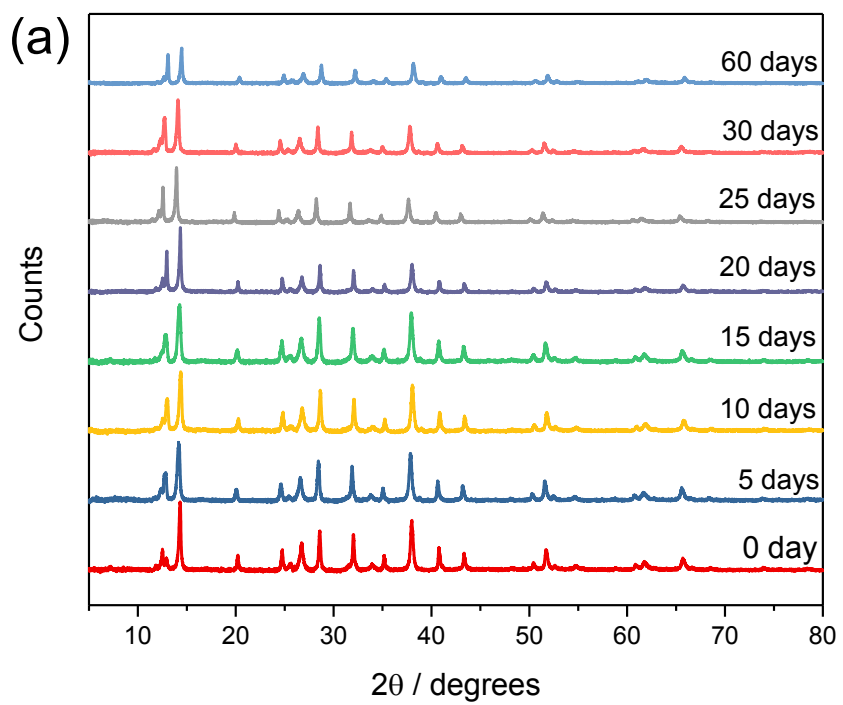




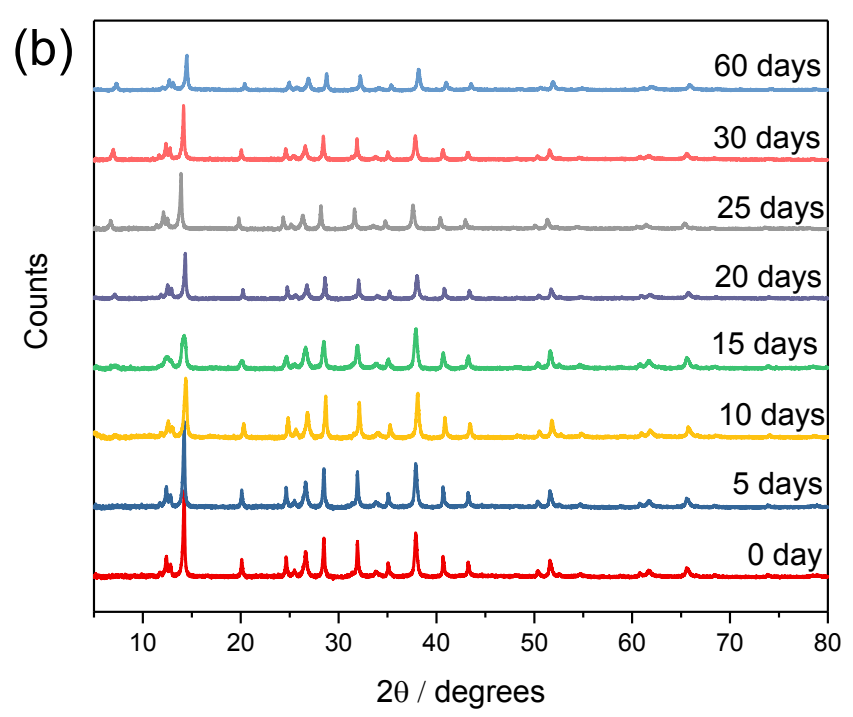

Figure S9. XRD tracking of (a) perovskite coated with reference HTL (SpiroOMeTAD/LiTFSI/TBP/FK209); (b) Perovskite coated with studied HTL (Spiro-OMeTAD/TBP/(MeOTPB)TFSI).

The ratio between (110) peak of perovskite at $14.34^{\circ}$ and (001) peak of lead iodide at $12.96^{\circ}$ was used to follow the perovskite decomposition process with a formula below:

Ratio $=\frac{\text { Height of }(110) \text { peak of Perovskite }}{\text { Height of (001) peak of } \mathrm{PbI}_{2}}$ 